\title{
Alteration in Material Properties of an Intact Rock due to Drilling and Bolting Operations
}

\author{
Lok Priya Srivastava and Mahendra Singh \\ Department of Civil Engineering, Indian Institute of Technology Roorkee, Roorkee 247667, India \\ Correspondence should be addressed to Lok Priya Srivastava; lpscivil@gmail.com
}

Received 13 February 2014; Accepted 21 April 2014; Published 19 May 2014

Academic Editor: Manoj Khandelwal

Copyright ( 2014 L. P. Srivastava and M. Singh. This is an open access article distributed under the Creative Commons Attribution License, which permits unrestricted use, distribution, and reproduction in any medium, provided the original work is properly cited.

\begin{abstract}
Rock material properties play an important role in assessing rock mass behaviour. Passive rock bolts stabilize a rock mass by restricting relative displacements; however, they may reduce rock material properties. While assessing properties of rock mass reinforced by rock bolts, the alteration caused in rock material properties due to drilling and bolting operation should be well understood. The present work makes an attempt to study the alteration in rock material properties due to drilling and bolting operations. The study has been conducted through physical tests on natural rock specimens in the laboratory. Virgin cylindrical specimens of intact rock were tested under uniaxial compression. Drilling was done through specimens and fully grouted bolts were installed. These specimens were also tested under uniaxial compression. It is observed that the drilling has substantial effect on the uniaxial compressive strength and modulus. A simple problem of tunnel is analysed which demonstrates the effect of alteration in material properties on the strength of rock mass around the tunnel in the field condition.
\end{abstract}

\section{Introduction}

Rock mass encountered in projects like tunnels and caverns generally consists of intact rock blocks separated by discontinuities (joints). Two important ingredients in stability analysis of rock mass are the rock material properties and the joint characteristics [1-4]. In many situations, the severity of jointing makes rock mass so incompetent that it becomes necessary to reinforce it. Rock bolts are extensively used for enhancing rock mass stability. Installation of bolts reduces relative displacement between rock blocks (Figure 1) and enhances the rock mass stability. Though there is overall improvement in stability of the rock mass, the rock material properties themselves alter due to drilling and bolting operations. Since rock material properties are important in assessing rock mass properties, the effect of alteration in material properties should be well understood by the designer. The drilling and bolting operations may affect the properties of intact rock material in the following manner.

(i) The vibrations induced during drilling by machine may create weak zones around the drill hole. (ii) The deduction of rock material for creating drill holes may induce weakness in the rock block.

As the hole is drilled through intact rock blocks, zone of weakness will develop around the hole. The grout and bolt filled in this hole will compensate to some extent the loss of strength, but it will not be equal to that which was gained through geological processes in forming the rock material. Due to the reasons mentioned above, the strength of rock material around the drill holes may reduce. There are some studies available in the literature, which have focused on the alteration of rock mass properties due to drilling process [510]; however, the alteration in rock material properties has not been considered.

The main aim of present study is to examine the effect of drilling and installation of bolts on rock material properties. For this purpose, cylindrical specimens of a natural rock have been prepared. Drilling was done through some of the specimens and the bolts were installed. The specimens were then tested under uniaxial compression to investigate the weakness brought into intact rock by installation of bolts. It is also emphasized that the purpose of bolting is to increase 


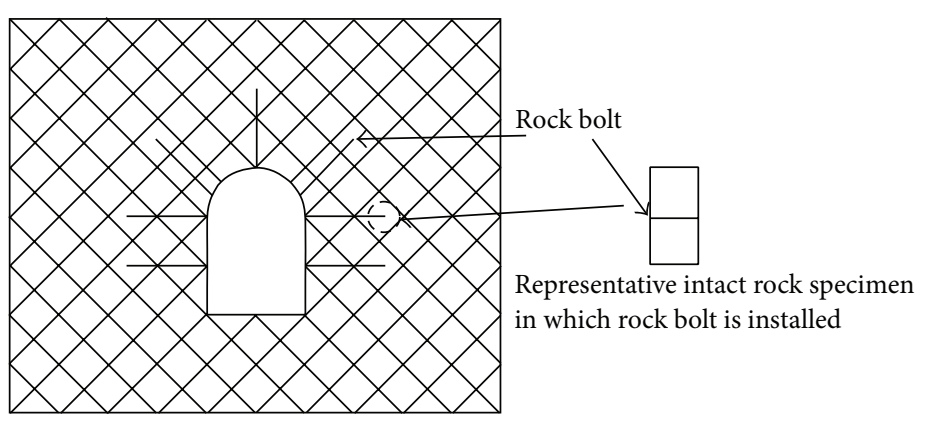

FIGURE 1: Rock bolts passing through intact rock blocks.

stability of rock mass with discontinuity and not the intact rock material, which does not have any discontinuity.

\section{Experimental Study}

To obtain the strength and modulus of deformation of intact rock material, without and with bolt, an experimental investigation has been carried out. Natural rock cores (Figure 2) have been retrieved from drill hole of a project site in the Garhwal region of the Indian Himalayas. The rock exposed at the project site is gneiss with bands of quartzite and schist. Visibly isotropic rock specimens were used for tests. The specimens for virgin and bolted condition were selected from the same depth. Cylindrical specimens with a height to diameter ratio two were prepared. For preparing bolted specimens, a hole of $6 \mathrm{~mm}$ diameter was drilled normal to the axis of the core. A steel bar of $4 \mathrm{~mm}$ diameter was used as a rock bolt and was installed into the specimens through this drill hole. The tensile strength of the steel bar is $550 \mathrm{MPa}$. The bolt was grouted with $1 \mathrm{~mm}$ thick cement mortar. The grout consists of cement, fine sand, and water having ratio of $2: 2: 1$ by weight. The specimens were left for 24 hours for initial setting of grout and then the other end of the bolt was tightened using nut washer system. As the grout takes time for setting, the specimens were left for air curing for 28 days. The sketch of prepared specimens is shown in Figure 3. These specimens were tested under uniaxial condition. The complete test setup of the test is shown in Figure 4. The tests were conducted by using an axial loading machine having a capacity of $2,000 \mathrm{kN}$, in displacement-controlled mode and at an axial displacement rate of $0.002 \mathrm{~mm} / \mathrm{sec}$. For each test, the axial load and axial displacement were recorded. The details of specimens used for tests are given in Table 1.

\section{Results and Discussion}

3.1. Failure Modes. Figure 5 shows the failure of virgin and bolted specimens under uniaxial compression. Most of the specimens failed in brittle manner. In case of bolted specimens, the fracture was initiated from the point where rock bolt was installed. It is inferred that drilling and installation of bolt create a weak zone in the intact material around drill hole. The failure of specimens is initiated from this weakened zone.

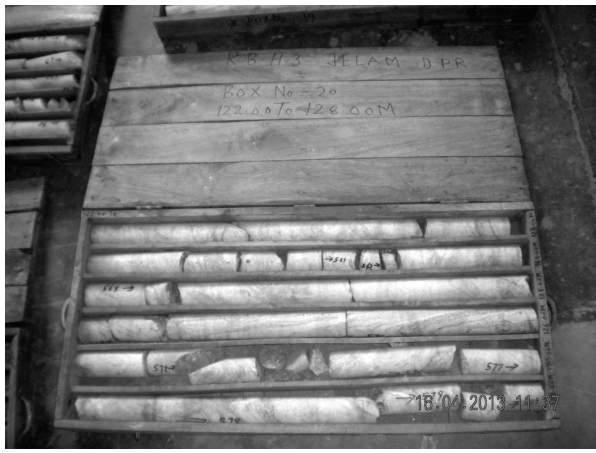

Figure 2: Cores of natural rock.

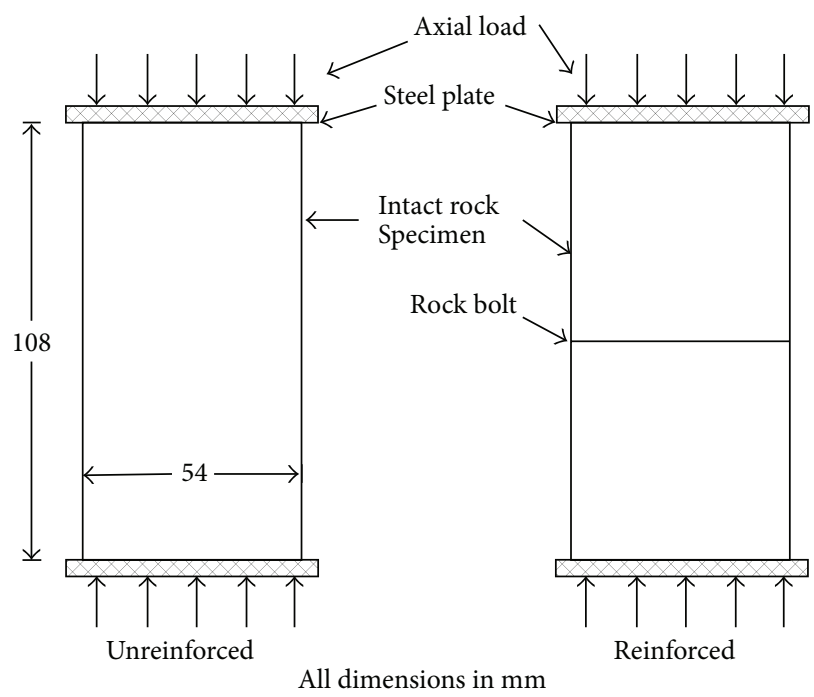

FIGURE 3: Virgin and bolted specimens.

3.2. Strength and Deformational Behaviour. Axial stress versus axial strain curves for few specimens are shown in Figure 6. The compression machine was programmed to record displacement only after reaching a load of $10 \mathrm{kN}$. The curves therefore indicate small stress at zero strain. In general, the peak stress has been found to have decreased due to drilling and bolting, whereas the failure strain has increased (expect some cases: Figure 6(b)). These plots were used to 
TABLE 1: Details of specimens tested.

\begin{tabular}{|c|c|c|c|c|c|}
\hline \multirow{2}{*}{ Serial number } & \multirow{2}{*}{ Depth in drill hole from ground surface $(\mathrm{m})$} & \multicolumn{2}{|c|}{ Specimen designation } & \multirow{2}{*}{ Diameter $(\mathrm{mm})$} & \multirow{2}{*}{ Length $(\mathrm{mm})$} \\
\hline & & Virgin & Bolted & & \\
\hline 1 & $17-18$ & $\mathrm{~T} 1 \mathrm{~V}$ & T1B & 58.8 & 117 \\
\hline 2 & $25-26$ & $\mathrm{~T} 2 \mathrm{~V}$ & $\mathrm{~T} 2 \mathrm{~B}$ & 58.8 & 117 \\
\hline 3 & $36-37$ & $\mathrm{~T} 3 \mathrm{~V}$ & T3B & 58.8 & 117 \\
\hline 4 & $64-65$ & $\mathrm{~T} 4 \mathrm{~V}$ & $\mathrm{~T} 4 \mathrm{~B}$ & 54 & 108 \\
\hline 5 & $79-80$ & $\mathrm{~T} 5 \mathrm{~V}$ & $\mathrm{~T} 5 \mathrm{~B}$ & 54 & 108 \\
\hline 6 & $88-89$ & T6V & T6B & 54 & 108 \\
\hline 7 & $113-114$ & $\mathrm{~T} 7 \mathrm{~V}$ & T7B & 54 & 108 \\
\hline 8 & $115-116$ & $\mathrm{~T} 8 \mathrm{~V}$ & T8B & 54 & 108 \\
\hline
\end{tabular}

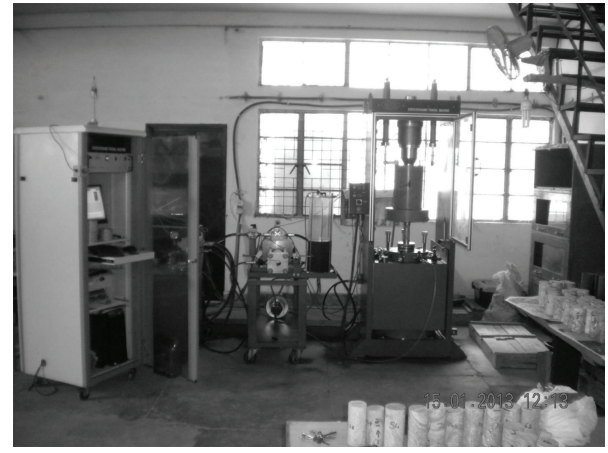

Figure 4: Setup of compression test.

obtain the tangent modulus at a stress level equal to $50 \%$ of failure stress.

The uniaxial compressive strength and tangent modulus of virgin and bolted specimens are summarized in Tables 2(a) and 2 (b), respectively. In these tables, the percent reduction in strength and modulus is also listed. The percent reduction in strength and modulus is defined as

$$
\begin{gathered}
\text { Percent reduction in strength }=\left(\frac{\sigma_{c}-\sigma_{c r}}{\sigma_{c}}\right) \times 100 \% \\
\text { Percent reduction in modulus }=\left(\frac{E_{c}-E_{c r}}{E_{c}}\right) \times 100 \%,
\end{gathered}
$$

where $\sigma_{c}$ is uniaxial compressive strength of virgin specimen, $\sigma_{c r}$ is uniaxial compressive strength of bolted specimen, $E_{c}$ is tangent modulus of virgin specimen, and $E_{c r}$ is tangent modulus of bolted specimen.

It is seen that the strength and the modulus of the virgin specimens is always greater than those for bolted specimens. It may be noted that for the specimens used in the present study, there was about 1 percent material deduction (volume of the grouted hole/volume of core $\times 100$ ) from the specimens for installation of bolts. The percent reduction in strength has varied from $0.77 \%$ to $69.21 \%$, while reduction in modulus varies from $2.44 \%$ to $67 \%$.

For a better representation of percent reduction in strength and modulus, the probability distributions of percent reduction in strength and modulus have been plotted (Figures $7(\mathrm{a})$ and $7(\mathrm{~b})$ ). For 50 percent probability, there
TABlE 2: (a) Uniaxial compressive strength of virgin and bolted specimens and percent reduction in strength. (b) Tangent modulus of virgin and bolted specimens and percent reduction in modulus.

(a)

\begin{tabular}{lccc}
\hline Serial number & $\sigma_{c}, \mathrm{MPa}$ & $\sigma_{c r}, \mathrm{MPa}$ & \% reduction in strength \\
\hline 1 & 23.58 & 22.18 & 5.94 \\
2 & 26.75 & 19.75 & 26.17 \\
3 & 33.79 & 33.53 & 0.77 \\
4 & 19.31 & 17.76 & 8.03 \\
5 & 108.08 & 38.44 & 64.43 \\
6 & 101.18 & 87.8 & 13.22 \\
7 & 122.85 & 37.83 & 69.21 \\
8 & 79.56 & 58.76 & 26.14 \\
\hline
\end{tabular}

(b)

\begin{tabular}{lccc}
\hline Serial number & $E_{c}, \mathrm{MPa}$ & $E_{c r}, \mathrm{MPa}$ & \% reduction in modulus \\
\hline 1 & 13000 & 5000 & 61.54 \\
2 & 6500 & 5000 & 23.08 \\
3 & 5330 & 5200 & 2.44 \\
4 & 5660 & 2600 & 54.06 \\
5 & 18600 & 6130 & 67.04 \\
6 & 15830 & 12500 & 21.04 \\
7 & 16740 & 6300 & 62.37 \\
8 & 12800 & 7000 & 45.31 \\
\hline
\end{tabular}

is a reduction of about $20 \%$ in strength and about $38 \%$ in modulus.

The overall reduction in strength and modulus indicates that the drilling and deduction of material for installation of bolts considerably affect the rock material properties and while modelling behaviour of reinforced rock mass, the altered properties of the rock material should be considered rather than the virgin properties.

\section{Example}

An example has been considered in this section to demonstrate the effect of alteration in rock material properties on the reinforced rock mass properties. Excavation of a tunnel has been modelled through 2D finite element analysis. The software package phase 2 has been used to analyse the 


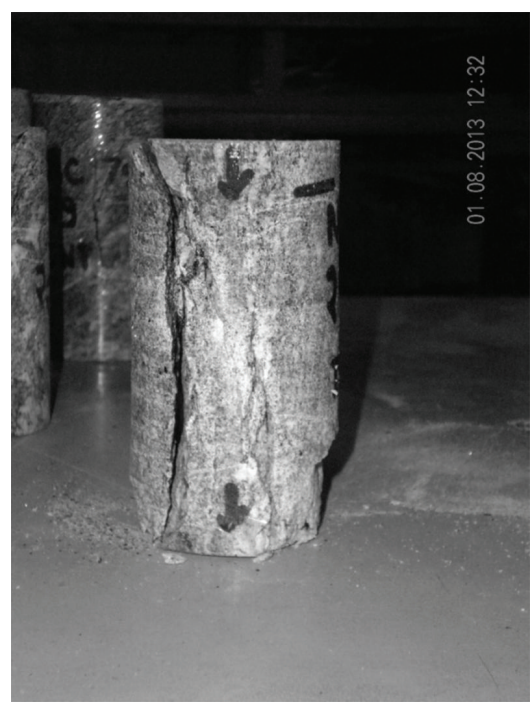

(a)

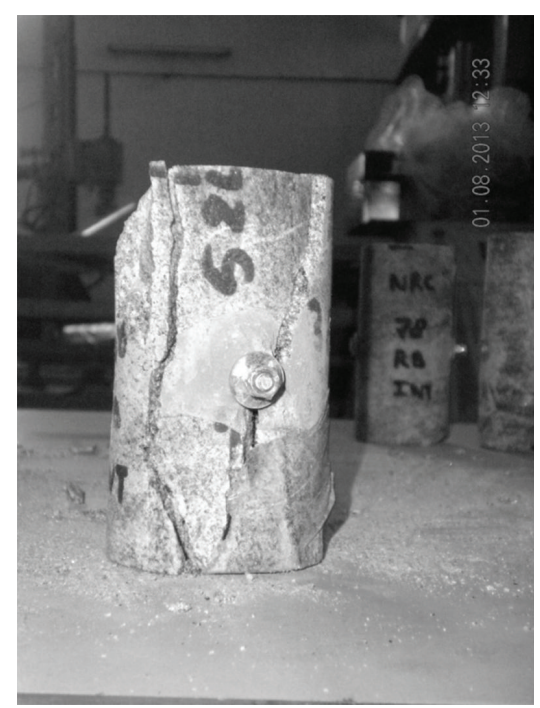

(b)

FIGURE 5: Failure of virgin and bolted specimens.

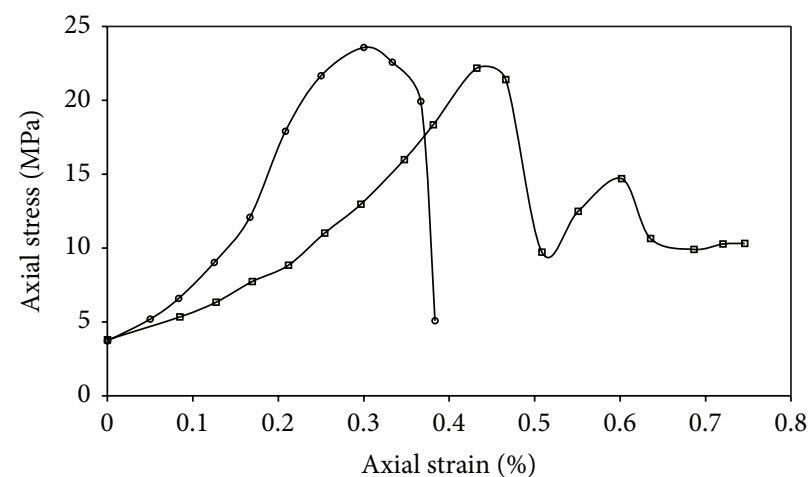

$\rightarrow \mathrm{T} 1 \mathrm{~V}$

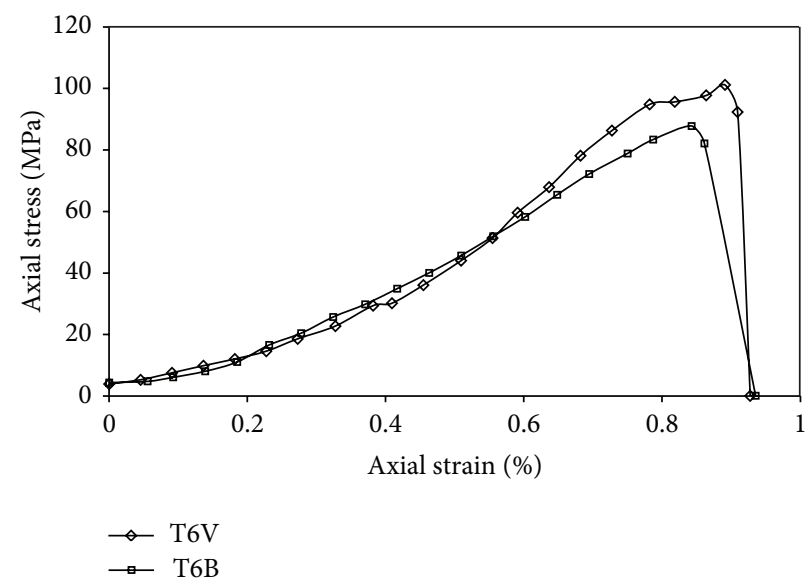

(b)

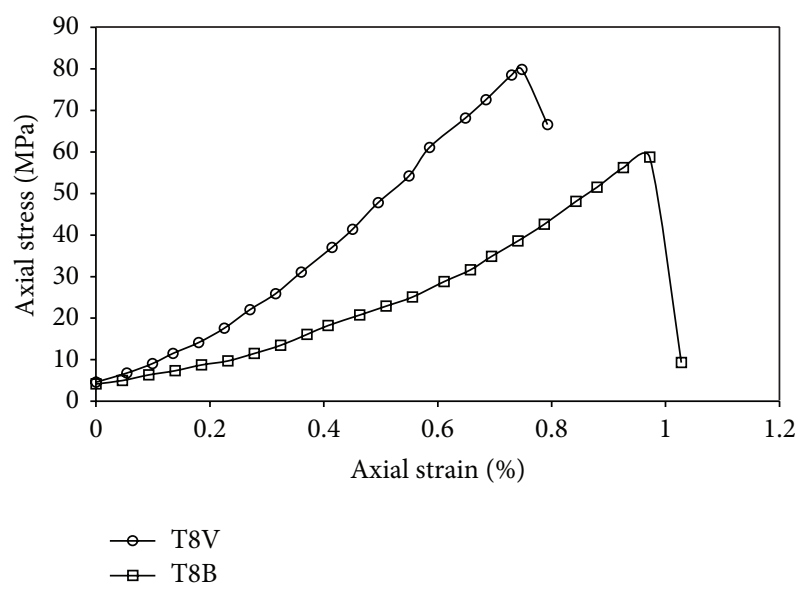

(c)

FIgURE 6: Axial stress versus axial strain curves for virgin and bolted specimens. 


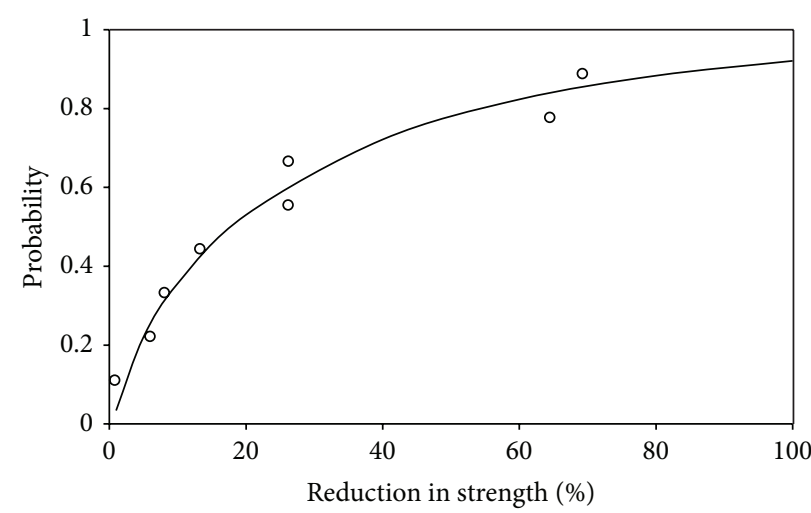

(a)

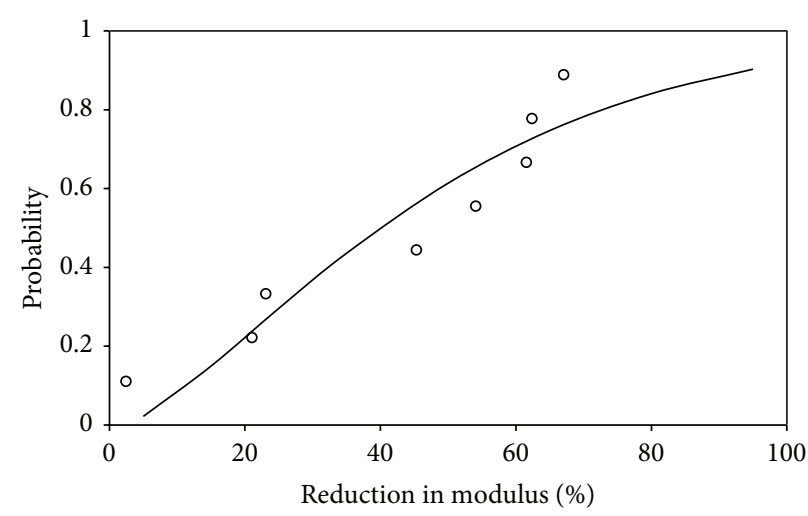

(b)

FIGURE 7: (a) Weibull distribution of percent reduction in strength. (b) Weibull distribution of percent reduction in modulus.

problem. The tunnel has been excavated in a rock mass and the following four cases have been considered.

Case I. Tunnel without rock bolts (Figure 8(a)).

Case II. Tunnel with rock bolts and without considering the alteration of rock material strength (Figure 8(b)).

Case III. Tunnel with rock bolts using altered values of material properties in the weak zones around bolts (Figure $8(\mathrm{c})$ ).

Case IV. Tunnel with rock bolts without altering rock material properties in weak zones around bolts and trial values of disturbance factor $(D)$ to get equivalent disturbance factor $(D)$ which will provide same effect as that by altering material properties.

The dimensions of the tunnel and external boundary are also shown in Figure 8(a). The input parameters for these cases are listed in Table 3.

Intact material properties used in the model are estimated from the laboratory uniaxial tests. The stresses in the field are $\sigma_{x x}=3.95 \mathrm{MPa}, \sigma_{y y}=9.65 \mathrm{MPa}$, and $\sigma_{z z}=5.93 \mathrm{MPa}$, respectively. Strength of rock mass subjected to given confining pressure has been obtained by using generalized HoekBrown criterion [11]. Also the modulus of the mass has been obtained by Hoek and Diederichs equation [12]. The parameters of the criterion are listed in Table 3(a). As GSI represents the condition of the rock mass in the field, only the uniaxial compressive strength and the modulus of intact rock have been changed and rest of the properties are kept the same. Hoek-Brown disturbance factor $(D)$ is used to characterize the degree of disturbance due to blast damage and stress relaxation. Hoek [13] suggested that this factor $D$ is only applicable in the blast-damaged zone, and it should not be applied to entire rock mass. Generally, in tunnels the blast-damaged zones are limited to 1 or $2 \mathrm{~m}$ around the tunnel boundary [13]. In present case, a damage zone has been created around the tunnel boundary, which extends up to $3 \mathrm{~m}$ in the rock mass from the boundary of the tunnel. In this zone a disturbance factor of 0.3 has been assumed. Passive cable bolts of $25 \mathrm{~mm}$ diameter are installed in the rock. The length
TABLE 3: (a) Properties of virgin rock mass and weaker zone around bolts. (b) Properties of rock bolts.

(a)

\begin{tabular}{lcc}
\hline Property & $\begin{array}{c}\text { Virgin rock } \\
\text { mass }\end{array}$ & $\begin{array}{c}\text { Zone around } \\
\text { bolts }\end{array}$ \\
\hline Unit weight $\left(\gamma, \mathrm{kN} / \mathrm{m}^{3}\right)$ & 27 & 27 \\
Intact UCS $\left(\sigma_{c}, \mathrm{MPa}\right)$ & 80 & 59 \\
Intact modulus $\left(E_{c}, \mathrm{MPa}\right)$ & 12800 & 7000 \\
GSI & 45 & 45 \\
$m_{i}$ & 12 & 12 \\
$D$ near tunnel periphery & 0.3 & 0.0 \\
$D$ away from tunnel periphery & 0.0 & - \\
$m_{b}$ near tunnel periphery & 1.683 & 1.683 \\
$m_{b}$ away from tunnel periphery & 1.190 & - \\
$s$ near tunnel periphery & 0.022 & 0.022 \\
$s$ away from tunnel periphery & 0.011 & - \\
$a$ & $0.51 / 0.51$ & 0.51 \\
\hline
\end{tabular}

(b)

\begin{tabular}{lc}
\hline Property & Value \\
\hline Bolt type & Plain strand cable \\
Borehole diameter, mm & 40 \\
Cable diameter, $\mathrm{mm}$ & 25 \\
Bolt modulus, $\mathrm{MPa}$ & 200000 \\
Cable peak, $\mathrm{MN}$ & 0.6 \\
Water $:$ cement ratio & 0.5 \\
Bolt length, $\mathrm{m}$ & 6 \\
Spacing, $\mathrm{m}$ & $1.5 \mathrm{~m} \mathrm{c} / \mathrm{c}$ in roof \\
& $2.5 \mathrm{~m} \mathrm{c/c} \mathrm{in} \mathrm{wall} \mathrm{and} \mathrm{floor}$ \\
\hline
\end{tabular}

and spacing of the bolts are calculated from the empirical relationship given by Hoek and Moy [14] as

For Roof $L=0.4 B$,

for wall $L=0.35 \mathrm{H}$, 


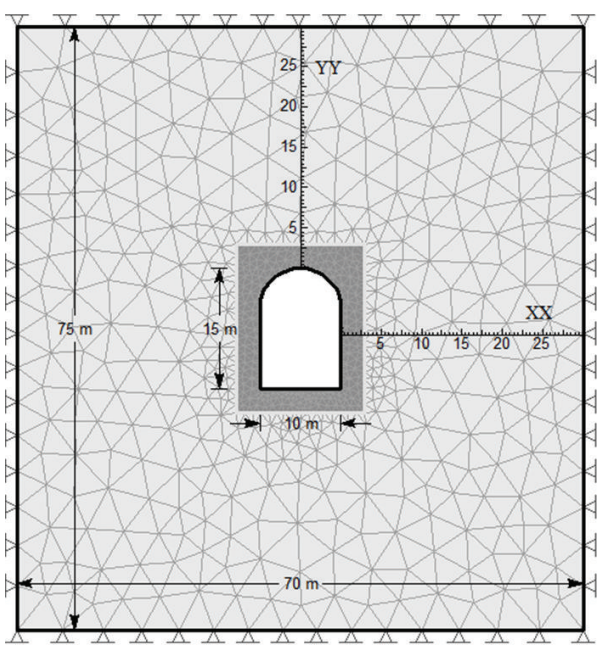

(a)

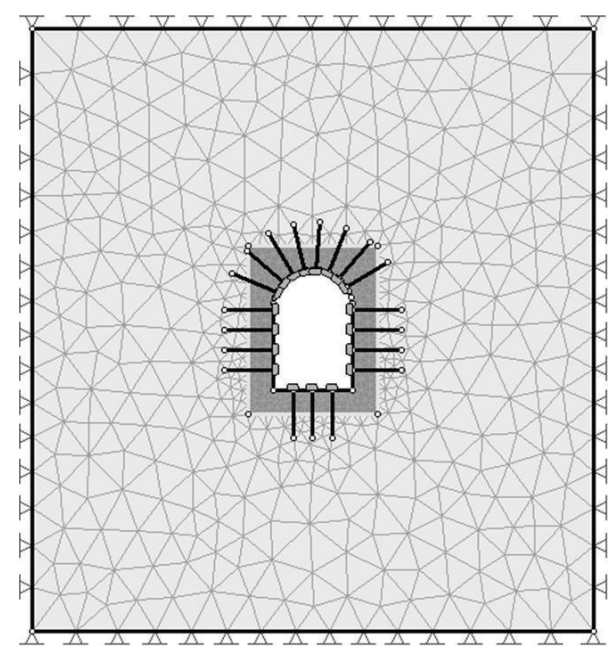

(b)

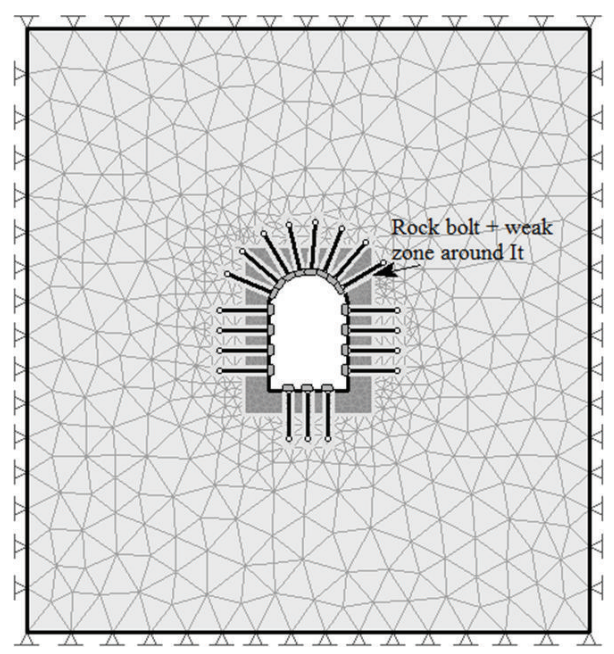

(c)

FIGURE 8: (a) Tunnel without bolts. (b) Tunnel with rock bolts without considering the effect of drilling on the strength of intact rock. (c) Tunnel with rock bolts plus weak zone around the bolt to consider the effect of drilling on the rock material properties.

where $L$ is the length of bolt, $H$ is the height of the tunnel, and $B$ is the width of the tunnel span. Based on above consideration a uniform length of bolt is adopted. The spacing of the bolts is kept as $<L / 2$. The properties of the bolts are listed in Table 3(b).

In the third case, weak zones are created around each bolt to consider the effect of drilling. The drilling for installation of bolts causes less damage to mass around the bolts compared to the damage caused by blasting or drilling for excavation of the face of tunnels. However, this depends on the type of machine used for drilling. In this study, the width of the weaker zone is taken roughly 25 times the diameter of the borehole.

Two points, one at the crown of the tunnel $(x=5, y=15)$ and the second at the boundary of the tunnel where the bolt is installed $(x=10, y=10)$, are selected to compare results. The comparison is presented in Table 4 . The contours of major principal stresses $\left(\sigma_{1}\right)$ and total displacement obtained in all cases are also presented in Figure 9. The variation of major principal stress and total displacement along sections XX and YY (Figure 8(a)) are also presented in Figure 10. From Figures 9-10, it is observed that the stresses and displacements are identical in all cases after a distance of $8 \mathrm{~m}$ from the tunnel boundary.

In Case I, an unreinforced tunnel is excavated through rock mass. This represents the condition when no rock bolts are installed into the rock mass. As the tunnel is excavated, the stress is redistributed around the boundary and a plastic zone develops around the periphery of the tunnel. The total displacement at crown is found to be $18 \mathrm{~mm}$. As one moves away from the periphery, the total displacement decreases and becomes constant after a distance of about $15 \mathrm{~m}$. The major and minor principal stresses at the crown are 8.45 and $0.74 \mathrm{MPa}$, respectively. Along section YY, the stresses increase up to $4 \mathrm{~m}$ and then decrease and become almost constant after $15 \mathrm{~m}$ from the tunnel periphery. At right and left side of tunnel (along section XX), the principal stresses increase and the total displacement decreases, as one moves away from 


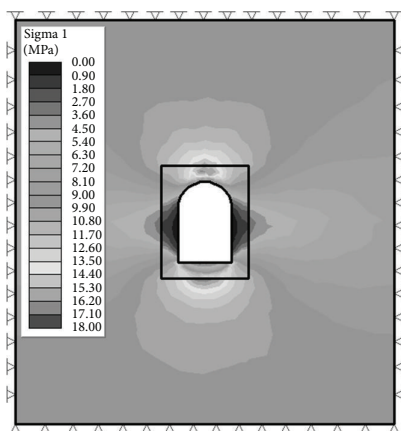

(A) Case I

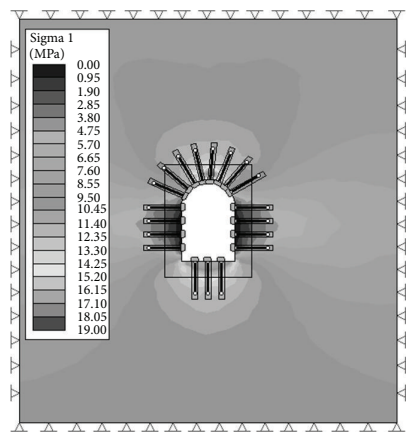

(C) Case III

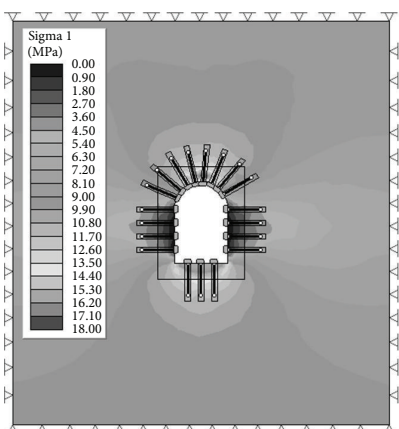

(B) Case II

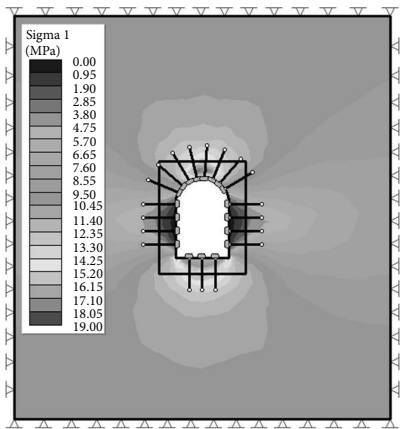

(D) Case IV

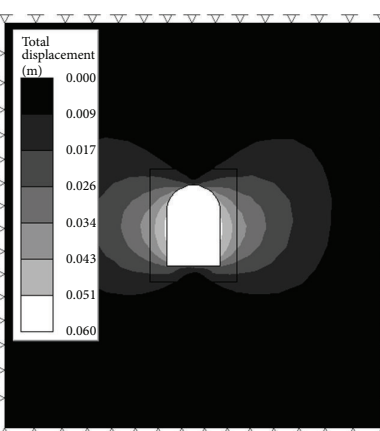

(A) Case I

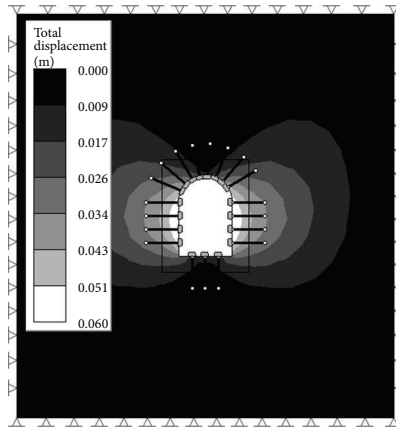

(C) Case III

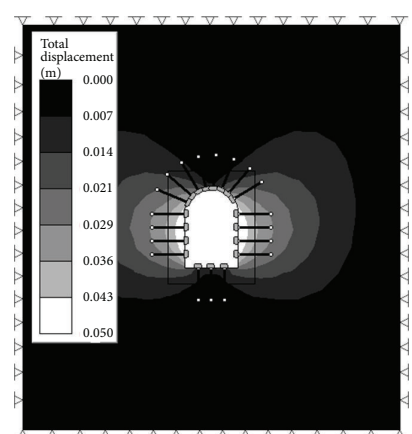

(B) Case II

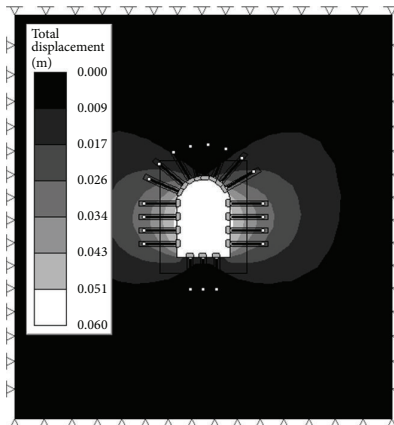

(D) Case IV

(a)

(b)

FIgURE 9: (a) Contour plots of major principal stress. (b) Contour plots of total displacement.

TABLE 4: Comparison of results for all cases.

\begin{tabular}{|c|c|c|c|c|c|c|c|c|}
\hline \multirow{2}{*}{ Parameters } & \multicolumn{2}{|c|}{ Case I } & \multicolumn{2}{|c|}{ Case II } & \multicolumn{2}{|c|}{ Case III } & \multicolumn{2}{|c|}{ Case IV } \\
\hline & $C$ & $R$ & C & $R$ & $C$ & $R$ & $C$ & $R$ \\
\hline$\overline{\sigma_{1}, \mathrm{MPa}}$ & 8.45 & 1.31 & 13.96 & 1.68 & 14.38 & 1.68 & 14.12 & 1.68 \\
\hline$\sigma_{3}, \mathrm{MPa}$ & 0.74 & 0.06 & 1.70 & 0.18 & 1.65 & 0.27 & 1.69 & 0.20 \\
\hline$\sigma_{z}, \mathrm{MPa}$ & 5.10 & 2.12 & 7.46 & 2.94 & 7.68 & 3.00 & 7.89 & 2.66 \\
\hline $\mathrm{HD}, \mathrm{m}$ & 0.001 & 0.049 & 0.000 & 0.046 & 0.000 & 0.052 & 0.000 & 0.048 \\
\hline $\mathrm{VD}, \mathrm{m}$ & 0.018 & 0.005 & 0.011 & 0.005 & 0.013 & 0.005 & 0.012 & 0.005 \\
\hline $\mathrm{TD}, \mathrm{m}$ & 0.018 & 0.049 & 0.011 & 0.046 & 0.013 & 0.052 & 0.012 & 0.049 \\
\hline
\end{tabular}

$C$ : at crown $(x=5, y=15) ; R$ : point right to crown $(x=10, y=10) ; \sigma_{1}$ : major principal stress; $\sigma_{3}$ : minor principal stress; $\sigma_{z}$ : out of plane principal stress; HD: horizontal displacement; VD: vertical displacement; TD: total displacement.

periphery. After a distance of $15 \mathrm{~m}$, the total displacement and the stresses become almost constant.

In Case II, the bolts are installed in the rock mass around the tunnel just after the excavation. Further movement of the rock mass around the tunnel periphery is suppressed by the provision of the bolts. Due to this, the stresses increase in the rock mass surrounding the periphery of the tunnel. Besides the development of plastic zone near tunnel periphery, compression zones are also developed between the bolts. The variation of major and minor principal stress and displacement with distance along periphery of the tunnel is similar to Case I, but the values of stresses and displacement are changed.

In Case III the alteration in material properties due to drilling has been considered around the bolts. In this case, the compression zones between bolts, the stresses are higher.
The deformation is also higher as compared to Case II. Due to alteration in properties, the area of plastic zone around the tunnel increases. The trend of variation of stresses and displacement is similar to Cases I and II, but their values are different.

Case IV has been modelled without alteration in rock material properties around bolts. Several trial values of disturbance factor $(D)$ have been adopted without altering the rock material properties. The purpose of the above analysis has been to work out an equivalent disturbance factor $D$, which would provide similar effect on stress distribution and deformation, as produced by considering alteration in rock material properties around bolts. The result of Case IV has been compared with Case III. Based on the results, an equivalent disturbance factor $D$ has been worked out which provides similar effect on stress distribution and deformation 


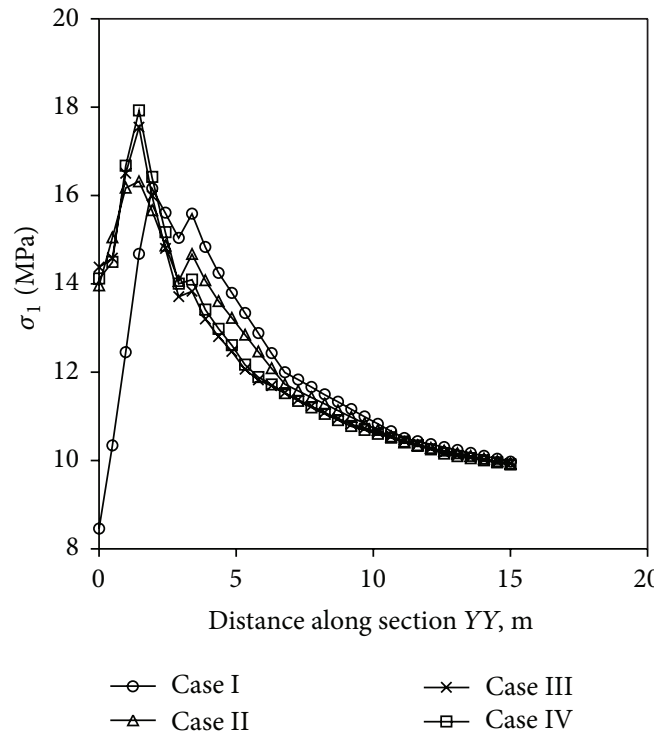

(A)

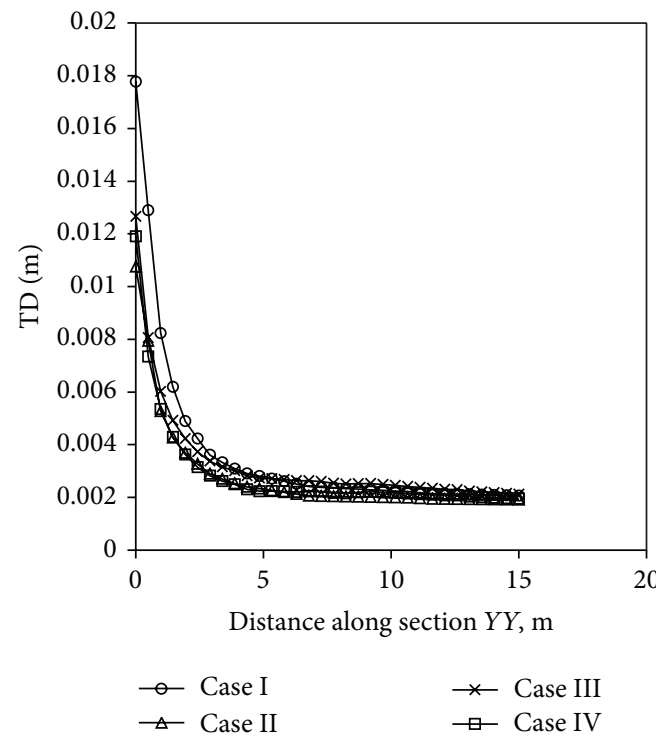

(A)

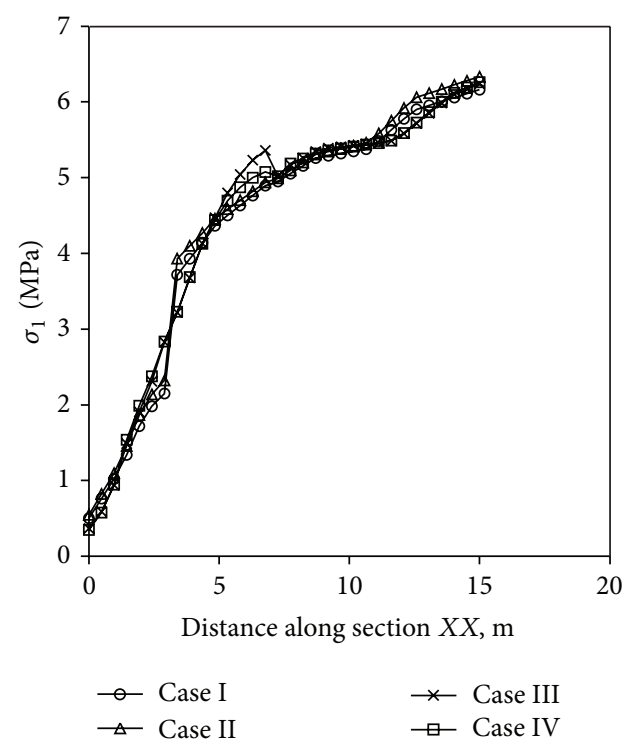

(B)

a)

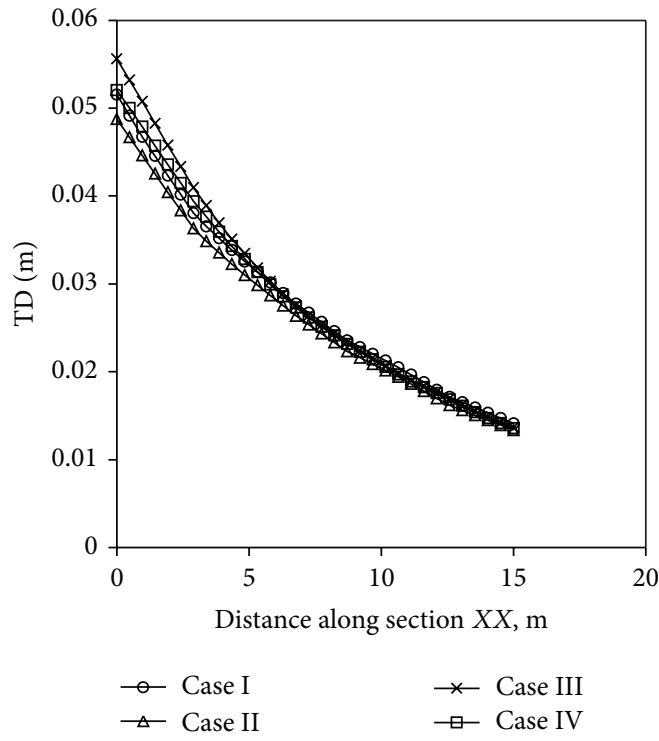

(B)

(b)

FIGURE 10: (a) Variation of major principal stress along boundary. (b) Variation of total displacement along boundary.

as produced by altering rock material properties in Case III. It is seen that when $D$ is approximately equal to 0.3 , results of Cases III and IV are almost identical. The alteration in rock material properties due to drilling around the bolts can, therefore, be modelled by suitably adopting the disturbance factor. Results suggest that the disturbance factor $(D)$ plays an important role in numerical modelling. Hence, to consider the effect of alteration in material properties due to drilling and bolting operations in the rock mass, an appropriate value of $D$ should be adopted.

\section{Concluding Remark}

Natural rock specimens have been tested to assess the alteration in rock material properties due to drilling and bolting operation. The study indicates substantial reduction in strength due to drilling and bolting. Assessment of stability of a reinforced mass warrants good understanding on material as well as discontinuity characteristics. The alteration brought into material properties should therefore be considered for making design more realistic. Through numerical analysis, 
it has been shown that this alteration could be modelled by considering the appropriate value of disturbance factor $D$ proposed by Hoek et al. [11]. It is therefore suggested that in addition to the factors like excavation/drilling damage and stress relaxation, the alteration in rock material properties should also be considered in deciding the disturbance factor D.

\section{Limitations}

Further studies are required especially for poor rock mass for precise quantitative assessment of disturbance factor $D$. In the present study, only one type of natural rock has been tested under uniaxial condition. For generalising the results, much more testing under different confining conditions is required with different types of rocks.

\section{Conflict of Interests}

The authors declare that there is no conflict of interests regarding the publication of this paper.

\section{Acknowledgments}

Financial support for some part of this study was received from Department of Science and Technology, New Delhi, under NRDMS Grant. The authors thank Dr. Bhoop Singh, Director, DST, for his cooperation and support for completion of the project. The authors also thank Dr. S. Sarkar and D. P. Kanungo, Scientists CBRI, Roorkee, for providing technical support for numerical analysis.

\section{References}

[1] T. Ramamurthy and V. K. Arora, "Strength predictions for jointed rocks in confined and unconfined states," International Journal of Rock Mechanics and Mining Sciences and, vol. 31, no. 1, pp. 9-22, 1994.

[2] P. H. S. W. Kulatilake, J. Um, B. B. Panda, and N. Nghiem, "Development of new peak shear-strength criterion for anisotropic rock joints," Journal of Engineering Mechanics, vol. 125, no. 9, pp. 1010-1017, 1999.

[3] M. Singh, K. S. Rao, and T. Ramamurthy, "Strength and deformational behaviour of a jointed rock mass," Rock Mechanics \& Rock Engineering, vol. 35, no. 1, pp. 45-64, 2002.

[4] M. Singh and K. S. Rao, "Empirical methods to estimate the strength of jointed rock masses," Engineering Geology, vol. 77, no. 1-2, pp. 127-137, 2005.

[5] J. P. Aglawe, Unstable and violent failure around underground openings in highly stressed ground [Ph.D. thesis], Queen's University, Kingston, Canada, 1999.

[6] J. Autio, H. Malmlund, M. Kemppainen, E. Oila, and M. Siitari-Kauppi, "Study of rock damage caused by drill and blast excavation at Aspo Hard Rock laboratory," Working Report 2004-33, University of Helsinki, 2004.

[7] S.-H. Chang, C.-I. Lee, and Y.-K. Lee, "An experimental damage model and its application to the evaluation of the excavation damage zone," Rock Mechanics \& Rock Engineering, vol. 40, no. 3, pp. 245-285, 2007.

[8] K. Fuenkajorn and J. K. Daemen, "Experimental assessment of borehole drilling damage in basaltic rocks," in Proceedings of the 25th U.S. Symposium on Rock Mechanics (USRMS '84), Evanston, Ill,USA, June 1984.

[9] S. P. Mathis and J. J. K. Daemen, Rock Damage Induced by Drilling: An Experimental Assessment of Potential Leakage around Borehole Seals, Department of mining and Geological engineering, University of Arizona, 1984.

[10] M. M. Sharma and R. W. Wunderlich, "The alteration of rock properties due to interactions with drilling-fluid components," Journal of Petroleum Science and Engineering, vol. 1, no. 2, pp. 127-143, 1987.

[11] E. Hoek, C. Torres, and B. Corkum, "Hoek-Brown criterion2002 edition," in Proceedings of the NARMS-TAC Conference, vol. 1, pp. 267-273, Toronto, Canada, 2002.

[12] E. Hoek and M. S. Diederichs, "Empirical estimation of rock mass modulus," International Journal of Rock Mechanics and Mining Sciences, vol. 43, no. 2, pp. 203-215, 2006.

[13] E. Hoek, "Practical Rock Engineering," 2007, http://www.rocscience.com.

[14] E. Hoek and D. Moy, "Design of large powerhouse caverns in weak rock," in Compressive Rock Engineering, vol. 5, pp. 85-110, Pergamon Press, Oxford, UK, 1993. 

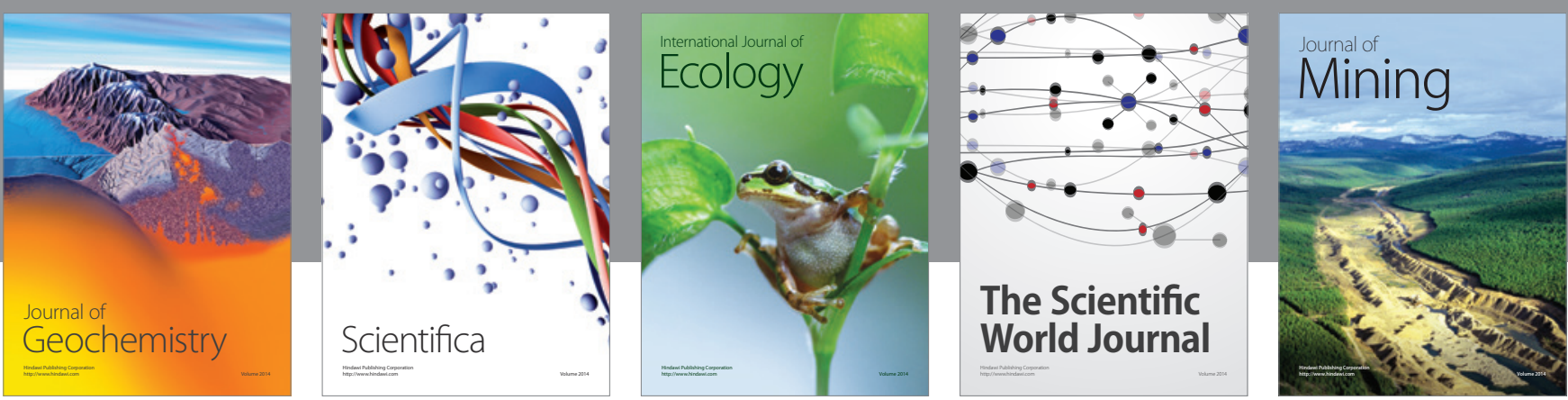

The Scientific World Journal
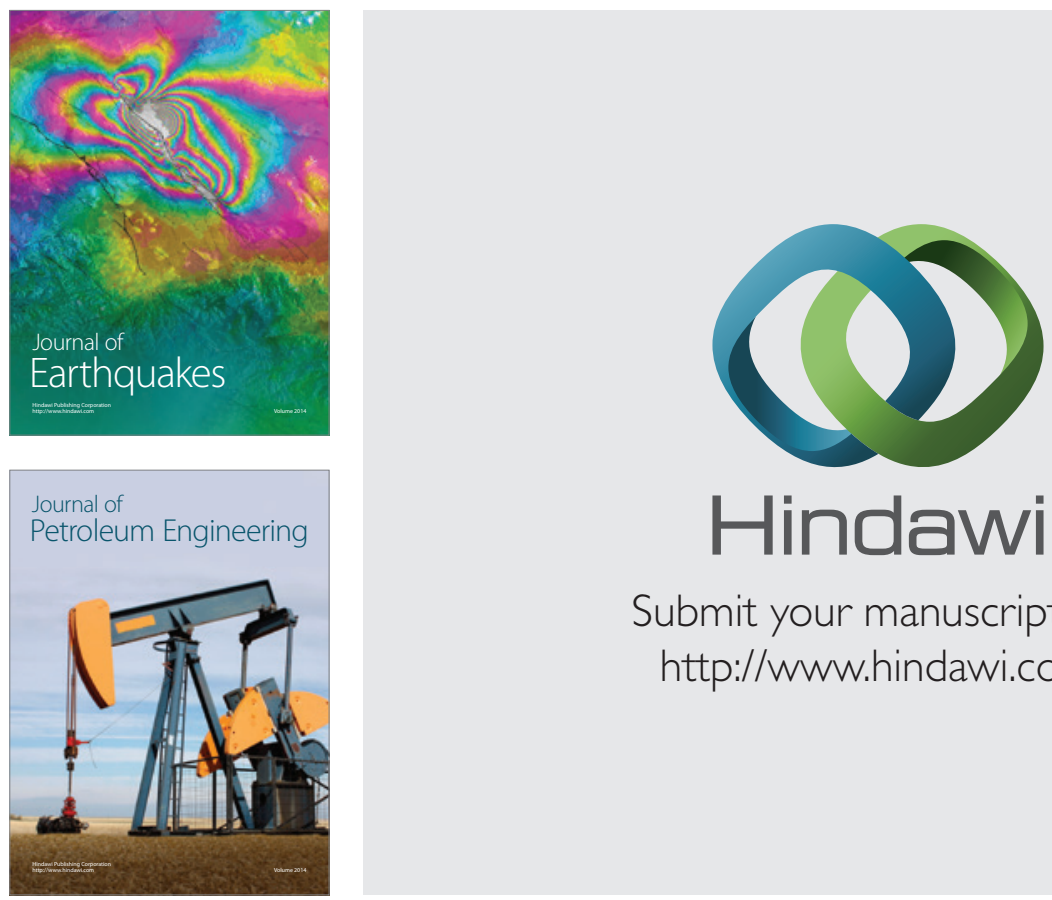

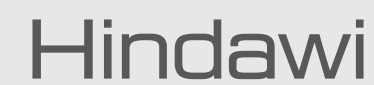

Submit your manuscripts at

http://www.hindawi.com
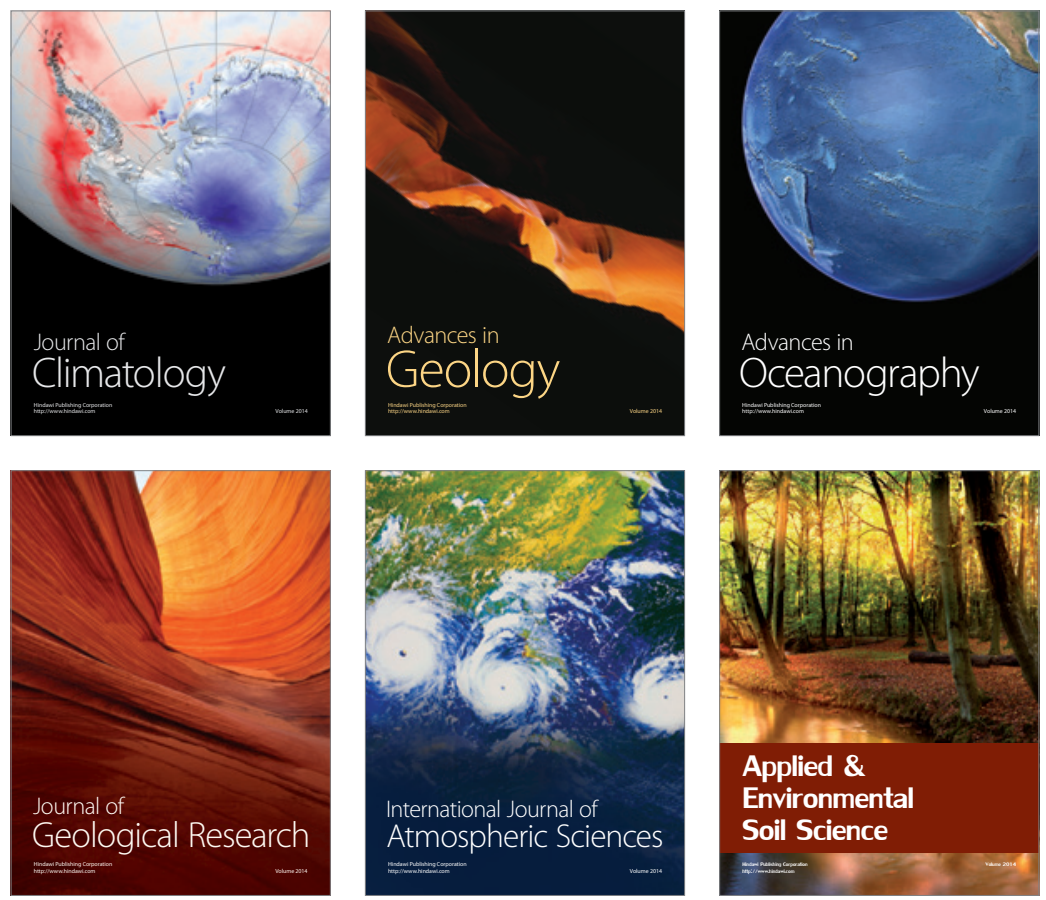
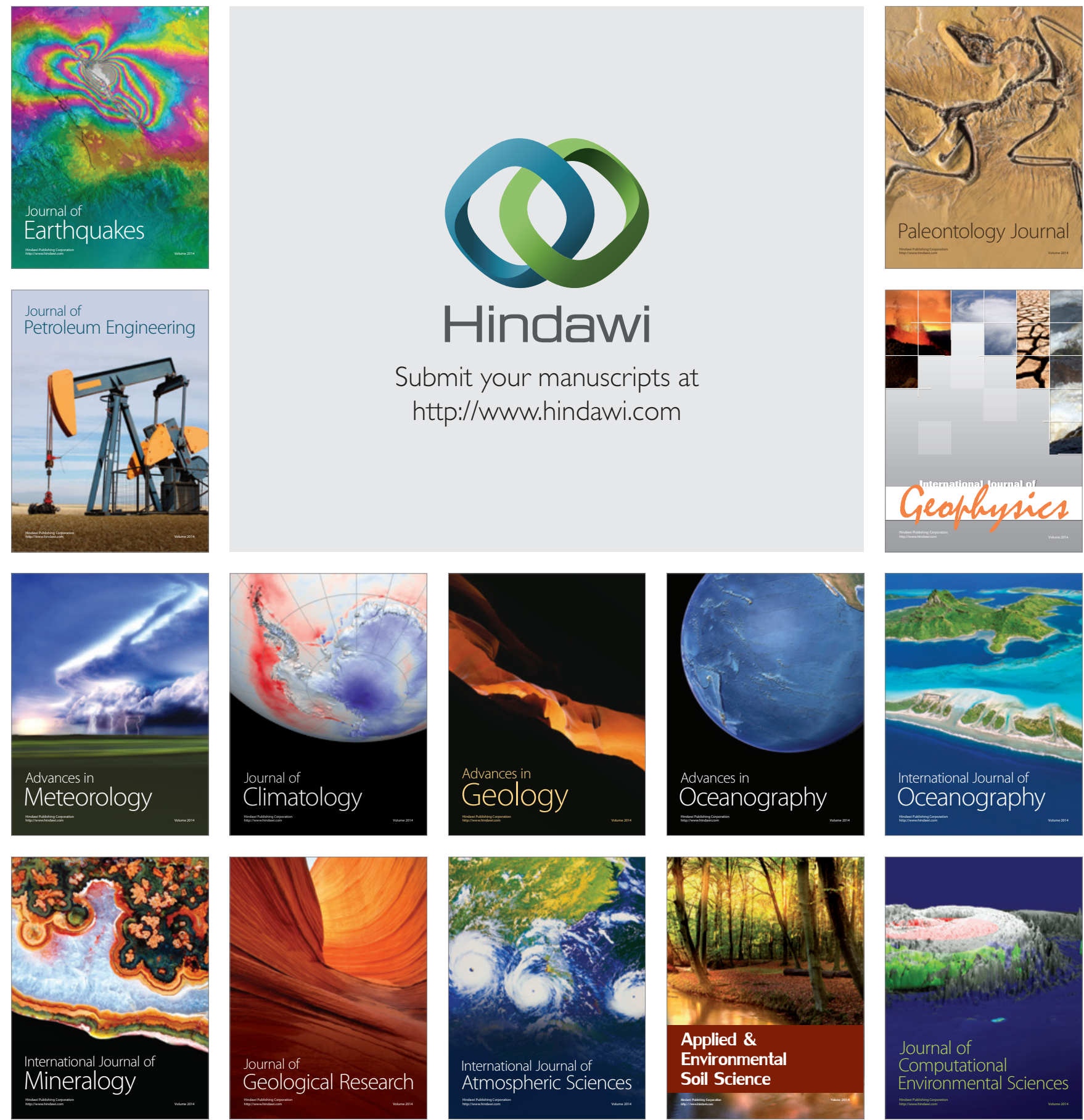